\title{
Comparison of Postoperative Pain after Root Canal Instrumentation Using M-Pro and ProTaper Next in Molars with Symptomatic Irreversible Pulpitis: A Randomized Clinical Trial
}

\author{
Mohammed Essam Othman ${ }^{1 *}$, Randa Mohammed Elboghdadi ${ }^{2}$ and \\ Shaimaa Ismail Gawdat ${ }^{3}$ \\ ${ }^{1}$ Master's student, Faculty of Dentistry, Cairo University, Cairo, Egypt \\ ${ }^{2}$ Professor of Endodontics, Head of Endodontic Department, Faculty of Dentistry, \\ Cairo University, Cairo, Egypt \\ ${ }^{3}$ Associate Professor of Endodontics, Faculty of Dentistry, Cairo University, Cairo, \\ Egypt \\ *Corresponding Author: Mohammed Essam Othman, Master's student, Faculty of \\ Dentistry, Cairo University, Cairo, Egypt.
}

Received: December 02, 2020

Published: December 28, 2020

(C) All rights are reserved by Mohammed

Essam Othman., et al.

\begin{abstract}
Aim: The aim of the present study was to clinically compare the postoperative pain after root canal preparation using M-pro rotary system and ProTaper Next rotary system in molars with symptomatic irreversible pulpitis.

Methods: A total of 50 patients with symptomatic irreversible pulpitis were included in the study. After clinical and radiographic examination, patients were assigned randomly into two groups ( $\mathrm{n}=25)$. In (Group A), root canals were instrumented with M-Pro rotary files. In (Group B), root canals were instrumented with ProTaper Next rotary files. All teeth were treated in a single visit. Pain was recorded by the Numerical Rating Scale preoperatively and at 6, 12, 24, 48, and 72 hours postoperatively. Placebo tablets were given to the patients to be taken in the case of mild pain and an analgesic was prescribed in case of an emergency. All demographic data, pain scores and number of analgesics tablets taken were collected from the patients. Data were analyzed using Chi-square test and Mann-Whitney U test.

Results: Results showed no statistically significant difference between the 2 groups regarding the postoperative pain or analgesic intake at all follow-up time intervals (P-value $>0.05$ ). There was a significant reduction in pain levels at all post-instrumentation follow up periods compared to preoperative pain level in both M-Pro and ProTaper Next groups (P-value $<0.0001$ ).

Conclusions: Postoperative pain resulting from the use of M-Pro rotary files was comparable to ProTaper Next rotary files and the pain intensity gradually decreased by time following endodontic treatment in both groups.
\end{abstract}

Keywords: Instrumentation; Irreversible Pulpitis; M-Pro; ProTaper Next; Postoperative Pain

\section{Abbreviations}

NRS: Numerical Rating Scale; NaOCl: Sodium Hypochlorite; EDTA: Ethylenediaminetetraacetic Acid; SPSS: Statistical Package for Social Science.

\section{Introduction}

The objective of root canal therapy is not only to preserve a tooth, that would be otherwise lost due to pulpal or periradicular disease but also to avoid postoperative pain. Postoperative pain is defined as the sensation of discomfort after endodontic intervention and is one of the common findings following endodontic treatment as reported by $25 \%-40 \%$ of patients regardless of pulp and peri-radicular condition [1,2]. Postoperative pain can be affected by multiple factors; one of these factors is the inadvertent extrusion of dentin chips, microorganisms or pulpal tissue remnants into the periapical region during preparation [3]. 
Comparison of Postoperative Pain after Root Canal Instrumentation Using M-Pro and ProTaper Next in Molars with Symptomatic Irreversible Pulpitis: A Randomized Clinical Trial

Several factors affect debris extrusion including the irrigation protocol, the size of apical enlargement, time of root canal preparation, the instrumentation technique and the instrument design [4]. In recent years, significant developments in rotary instrumentation and metallurgy have led to the introduction of various devices with revolutionary designs. Nevertheless, a degree of extrusion of debris is still associated with all the preparation techniques and instruments available to date [5-7].

One of the recently introduced rotary file systems is the M-Pro ${ }^{\circledR}$ rotary system (Innovative Materials and Devices, Shanghai, China). According to the manufacturer, it is made from $\mathrm{X}$-wire material that is manufactured from a special heat treatment that allows the file to be pre-bendable and increases the strength of the file. It has a convex triangular cross-section and increasing pitch from the tip shaft, the manufacturer claims that this allows the debris to be transported out of the canal as the file advances apically [8].

The ProTaper Next files (Dentsply Tulsa Dental Specialties, USA) operate in continuous rotary motion, and their center of rotation is positioned off-center relative to the instrument's central axis of rotation. During rotation, these files produce a mechanical wave of motion, which travels along the length of the instrument, minimizing the contact between the file and dentin. According to the manufacturer, the offset design of this instrument also improves debris removal and flexibility in the working part of the file [9].

While several in vivo studies have assessed the effect of using ProTaper Next files on postoperative pain, to our knowledge there are no clinical studies on the effect of instrumentation using M-pro files on postoperative pain. Furthermore, these newly introduced files can provide more affordable means for instrumentation. Therefore, the purpose of this study was to compare the effect of using M-Pro files and Pro-Taper Next files on postoperative pain in molars with symptomatic irreversible pulpitis.

\section{Subjects and Methods}

Sample size calculation and informed consent

The protocol of the trial was approved by the Ethics committee, Faculty of Dentistry, Cairo University (18/10/1), each patient received a full explanation of the treatment procedures and the associated possible discomforts. The patient was asked to follow general instructions and to sign a printed informed consent ex- plaining the aim of the study and obligating the patients to fill the pain diary chart. The study was registered at www.clinicaltrials. gov (NCT03692039). The sample size was determined using a previous study [10] in which the difference in postoperative pain score between the groups is $1 \pm 1$. Using power $80 \%$ and $5 \%$ significance level we will need to study 17 in each group. This number is to be increased to a sample size of 20 to adjust for using a nonparametric test. The number is to be increased again to a sample size of 25 in each group to compensate for losses during follow-up (25\% more than the calculated). Sample size calculation was achieved using PS: Power and Sample Size Calculation Software Version 3.1.2 (Vanderbilt University, Nashville, Tennessee, USA).

\section{Eligibility criteria}

Healthy patients between 18-45 years old with lower molars (first and second molars) with symptomatic irreversible pulpitis and 4 root canals were only included. Normal periapical radiographic appearance or slight widening in lamina dura were also checked.

The exclusion criteria included patients who have already consumed preoperative medication, such as analgesics, non-steroidal or steroidal anti-inflammatory drugs, within 12 hours before treatment, patients who are allergic to non-steroidal anti-inflammatory drugs, teeth associated with swelling or fistulous tract, teeth with more than grade I mobility or pocket depth more than $5 \mathrm{~mm}$, nonrestorable teeth and teeth with periapical radiolucency.

For each tooth, the diagnosis of symptomatic irreversible pulpitis was made from the chief complaint and the clinical examination. Preoperative pain was the main diagnostic sign of symptomatic irreversible pulpitis. The Numerical Pain Rating Scale (NRS) is a single 11-point numeric scale, with 0 indicating no pain and 10 reflecting the worst possible pain. All patients were given a Numeric rating scale, for the evaluation of pain where "7-10" referred for severe pain which is indicated for the study eligibility.

Pulp sensitivity was confirmed by a positive response to ethyl chloride spray cold pulp testing and a sharp, severe, lingering painful response confirmed the diagnosis of symptomatic irreversible pulpitis. Periapical status was examined via periapical radiographs, and radiographic examination revealed healthy periapical tissues with no periapical radiolucency. 
Comparison of Postoperative Pain after Root Canal Instrumentation Using M-Pro and ProTaper Next in Molars with Symptomatic Irreversible Pulpitis: A Randomized Clinical Trial

Randomization

The sequence generation for the patients' numbers was done using a random sequence number generated by computer software, (http://www.random.org/) and the table was kept with the assistant supervisor. Following applying local anaesthesia, access cavity preparation and confirming the presence of 4 root canals, the participant was confirmed eligible for the study and was given a number from 1 to 50 . Based on this number the patient was then allocated to either (Group A) or (Group B) after contacting the table keeper to reveal the assigned group of the current patient number. The assistant supervisor was the one who generated the random sequence and assigned the participants to either group.

Due to the nature of the interventions, the operator who performed the treatment procedures was not blinded to the interventions. However, the patients were blinded and not informed of the allocation, also the statistician was blinded to the intervention made in each group.

\section{Procedural steps}

After the preoperative pain for each patient was scored using the Numeric Rating scale (NRS), local anaesthesia was achieved by using $1.8 \mathrm{ml}$ of 2\% Mepivacaine $\mathrm{HCl}$ with 1: 100,000 epinephrine (Alexandria Co. for Pharmaceuticals, Alexandria, Egypt) through an inferior alveolar nerve block. Rubber dam was placed to isolate the tooth and an access cavity was performed with a high-speed handpiece using round bur and Endo-Z bur (Dentsply Maillefer, Ballaigues, Switzerland).

The canals were explored with \#10 or \#15 K-type hand files (MANI, INC. Industrial Park, Utsunomiya, Tochigi, Japan) in a watch-winding motion. The presence of 4 root canals was confirmed. The working length (WL) was established by an apex locator (Root ZX, J. Morita, USA) and then confirmed radiographically. All instruments were driven by X-Smart motor (Dentsply Maillefer, Ballaigues, Switzerland). Torque limits and rotation speed were set individually for each file system used. All files were introduced in the canal using EDTA gel (Meta Biomed Co. Ltd, Korea).

Instrumentation protocols

- $\quad$ Experimental group (M-Pro group): In the presence of the irrigant, the first file (18/.09) was used as an orifice opener for two-thirds of the working length followed by (20/.04) for the full working length and finally (25/.06). In-and-out motions were applied with stroke lengths not exceeding $3 \mathrm{~mm}$ until attaining the established WL. The first file was used with a continuous rotary motion at a speed of $500 \mathrm{rpm}$ and torque of $3 \mathrm{Ncm}$. The second and third files were used with a speed of $500 \mathrm{rpm}$ and a torque of $1.5 \mathrm{Ncm}$.

- Comparator group (ProTaper Next): The ProTaper Next X1 (17/.04) file was used to brush the canals, along the glide path, in one or more passes, alternatively with small-sized hand files if necessary, until the working length was reached. X2 file (25/.06) was used till the working length for finishing the preparation. The files were used in a continuous rotary brushing motion at a speed of $300 \mathrm{rpm}$ and a torque of $2 \mathrm{Ncm}$. The preparations for all the canals were finished using the third file in the M-Pro system or ProTaper Next X2 file.

Irrigation was done using $3 \mathrm{ml}$ of $2.5 \% \mathrm{NaOCl}$ solution between every file used and introduced to the canal using a 27-gauge side vented needle. Final flush of $1 \mathrm{ml}$ EDTA 17\% solution (Prevest Denpro Limited, Jammu, India) for 1 minute, irrigation with a saline solution was done in between the $\mathrm{NaOCl}$ and EDTA to prevent them from reacting together.

All canals were dried with paper points and master cones of gutta-percha for M-Pro and ProTaper Next groups were corresponding to the final shaping file used, (25/.06) (Meta Biomed Co. Ltd, Korea) and X2 (Dentsply Tulsa Dental specialities, USA) respectively. A radiograph was taken to ensure proper length. The canals were then obturated with the modified single cone technique and AdSeal resin-based root canal sealer (Meta Biomed Co. Ltd, Korea). The treatment was concluded by sealing the access cavity with a temporary filling (Meta Biomed Co. Ltd, Korea).

The patients were given a capsule of placebo to be taken in the event of mild pain and Ibuprofen (400mg) was prescribed to be administered in case of emergency. The patients were asked to record the following information $6,12,24,48$ and $72 \mathrm{hrs}$ after the treatment: their pain rating on the Numeric Rating Scale and whether they had taken the Placebo prescribed and/or the analgesic medication and, if so, the number of tablets. 
Comparison of Postoperative Pain after Root Canal Instrumentation Using M-Pro and ProTaper Next in Molars with Symptomatic Irreversible Pulpitis: A Randomized Clinical Trial

\section{Statistical analysis}

Statistical analysis was performed using IBM SPSS advanced statistics, version 24 (SPSS Inc., Chicago, IL). Continuous data were tested for normality using Shapiro Wilk and Kolmogrov Smirnov tests. Mean and standard deviation values were used for data presentation and Mann - Whitney U test was used for comparison between the two groups. Categorical data were presented as frequencies and percentages and Chi-square test was used for comparison between the two groups.

\section{Results}

No patients were lost during follow-up, 50 patients were enrolled in this study and randomly divided into 2 groups $(n=25)$. The flow of participants is represented in consort flow diagram (Figure 1).

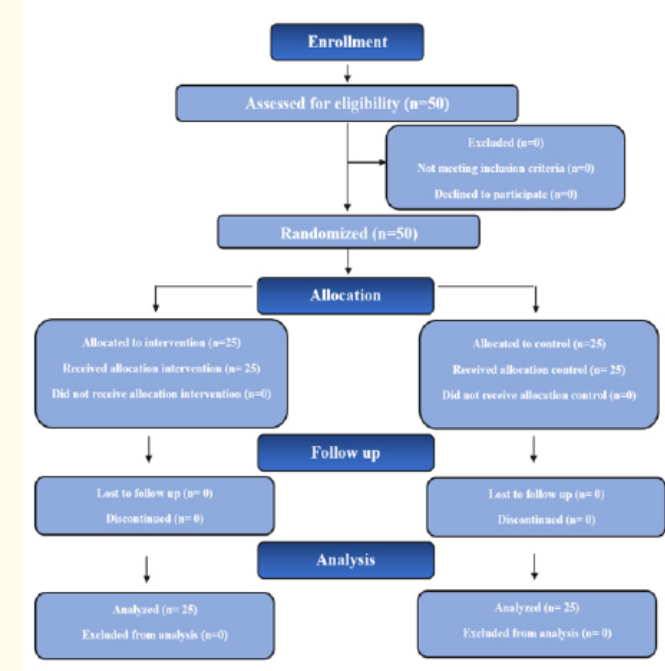

Figure 1: CONSORT Flow diagram of the trial design.

\section{Baseline data}

No statistically significant differences were found between the groups in terms of baseline data (age, sex and tooth type) $(\mathrm{P}>.05)$ (Table 1).

Outcome data

There was no statistically significant difference between the two groups preoperatively and at 6, 12, 24, 48 and 72 hours postoperatively (Table 2) (Figure 2). There was no statistically significant difference between the two groups regarding the incidence of placebo or analgesic intake (Table 3). Comparing changes in pain

\begin{tabular}{|c|c|c|c|}
\hline & $\begin{array}{l}\text { Group A } \\
\text { (M-Pro) } \\
(n=25)\end{array}$ & $\begin{array}{c}\text { Group B } \\
\text { (ProTaper } \\
\text { Next) } \\
(n=25)\end{array}$ & P-value* \\
\hline $\begin{array}{l}\text { Age (Years) } \\
\text { Mean } \pm \text { Std. } \\
\text { Dev }\end{array}$ & $27.2(6.5)$ & $28.9(6.3)$ & 0.297 \\
\hline $\begin{array}{c}\text { Gender [n } \\
\text { (\%)] } \\
\text { Males } \\
\text { Females }\end{array}$ & $\begin{array}{c}7(28 \%) \\
18(72 \%)\end{array}$ & $\begin{array}{c}7(28 \%) \\
18(72 \%)\end{array}$ & 1.000 \\
\hline $\begin{array}{l}\text { Tooth type } \\
\text { [n (\%)] } \\
1^{\text {st }} \text { molar } \\
2^{\text {nd }} \text { molar }\end{array}$ & $\begin{array}{c}23(92 \%) \\
2(8 \%)\end{array}$ & $\begin{array}{l}20(80 \%) \\
5(20 \%)\end{array}$ & 0.221 \\
\hline
\end{tabular}

Table 1: Mean, standard deviation (Std. Dev), frequencies (n), percentages and results of Mann-Whitney test and Chi-square test for comparisons of baseline data in the two groups.

*Significant at $\mathrm{P}$-value $\leq 0.05$

scores with time in both groups revealed a significant reduction in pain intensity between preoperative and all postoperative pain scores in both groups (P-value $<0.0001$ ) (Figure 3).

\begin{tabular}{|c|c|c|c|}
\hline \multirow{2}{*}{$\begin{array}{c}\text { Observation } \\
\text { period }\end{array}$} & \multicolumn{2}{|c|}{ Mean \pm Std. Dev } & \multirow{2}{*}{ P-value } \\
\cline { 2 - 3 } & $7.8 \pm 1.6$ & $\begin{array}{c}\text { ProTaper } \\
\text { Next }\end{array}$ & \\
\hline Preoperative & $3.3 \pm 2.7$ & $3 \pm 2.4$ & 0.714 \\
\hline $\begin{array}{c}\text { 6 hours } \\
\text { postoperatively }\end{array}$ & $3.5 \pm 2.2$ & $3.6 \pm 2.4$ & 0.806 \\
\hline $\begin{array}{c}12 \text { hours postopera- } \\
\text { tively }\end{array}$ & $2.8 \pm 2.1$ & $2.6 \pm 2.3$ & 0.705 \\
\hline $\begin{array}{c}24 \text { hours postopera- } \\
\text { tively }\end{array}$ & $0.9 \pm 1.8$ & $1.3 \pm 2$ & 0.481 \\
\hline $\begin{array}{c}48 \text { hours postopera- } \\
\text { tively }\end{array}$ & $0.4 \pm 1.5$ & $0.7 \pm 1.5$ & 0.277 \\
\hline $\begin{array}{c}72 \text { hours postopera- } \\
\text { tively }\end{array}$ & & \\
\hline
\end{tabular}

Table 2: Mean, standard deviation values and the results of MannWhitney U test for comparison of NRS scores at different observation periods between the two groups.

*Significant at P-value $\leq 0.05$. 
Comparison of Postoperative Pain after Root Canal Instrumentation Using M-Pro and ProTaper Next in Molars with Symptomatic Irreversible Pulpitis: A Randomized Clinical Trial

\begin{tabular}{|c|c|c|c|}
\hline & $\begin{array}{c}\text { Group A ( } \\
\text { M-Pro) } \\
\text { (n = 25) }\end{array}$ & $\begin{array}{c}\text { Group B ( } \\
\text { ProTaper Next) } \\
\text { (n = 25) }\end{array}$ & P-value* \\
\hline $\begin{array}{c}\text { Placebo } \\
\text { intake [n } \\
\text { (\%)] } \\
\text { Yes }\end{array}$ & $7(28 \%)$ & $10(40 \%)$ & 0.370 \\
No & $18(72 \%)$ & $15(60 \%)$ & \\
\hline $\begin{array}{c}\text { Analgesic } \\
\text { intake [n } \\
\text { (\%)] } \\
\text { Yes }\end{array}$ & $3(12 \%)$ & $5(20 \%)$ & 0.440 \\
No & $22(88 \%)$ & $20(80 \%)$ & \\
\hline
\end{tabular}

Table 3: Frequencies, percentages and results of chi-square test for comparison of placebo and analgesic intake in the two groups. *Significant at $\mathrm{P}$-value $\leq 0.05$.

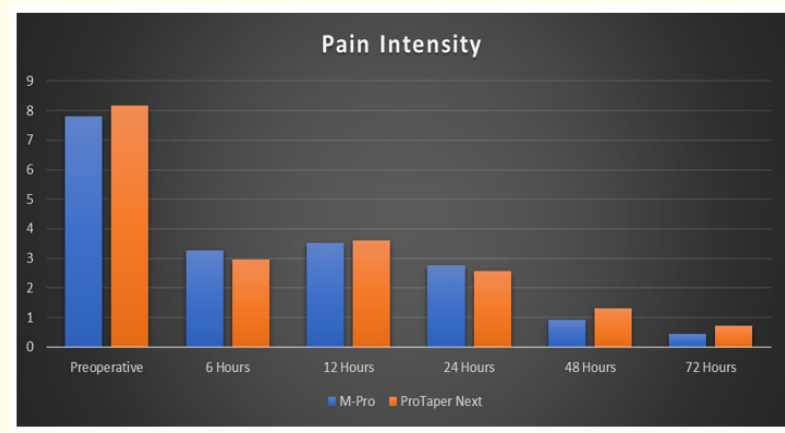

Figure 2: Bar chart representing the mean NRS scores at different observation periods postoperatively in the two groups.

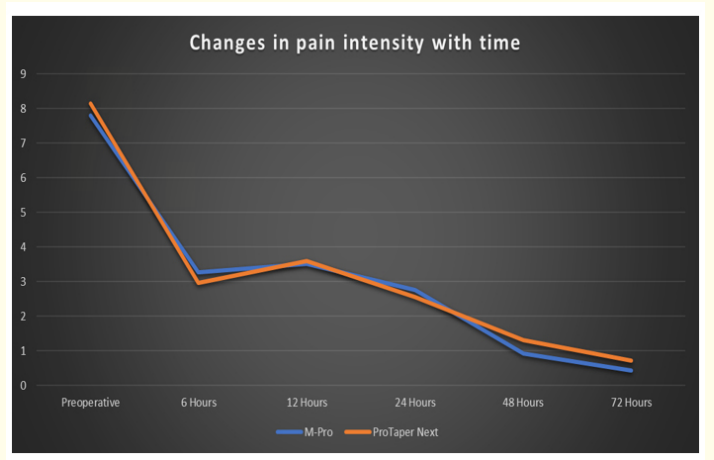

Figure 3: Line chart representing the changes in pain intensity with time in both groups.

\section{Discussion}

The success of endodontic therapy cannot be judged only on its efficacy and adequate completion but also the minimal discomfort to the patient. Several factors including sex, age, type of tooth, pulp and periradicular condition, preoperative pain, and technical aspects may affect the occurrence of postoperative pain. Among these factors, only technical aspects including instrumentation, irrigation, and obturation protocols are controlled by the operator [11].

Apical debris extrusion during instrumentation may lead to inflammation of the peri-radicular tissues leading to post-operative pain and flare-ups $[12,13]$. While all rotary files in the market are associated with some degree of extrusion of debris, a rotary file system that reduces the risk of debris extrusion into periapical tissues would help patients and clinicians because the system could decrease postoperative pain. When a literature search was conducted, several clinical trials evaluated the effect of ProTaper Next files on postoperative pain. While the recently introduced M-Pro rotary file system's effect on postoperative pain is yet to be studied to our knowledge. So this study aimed to compare postoperative pain after single-visit treatment with M-Pro and ProTaper Next rotary files.

The present study was a prospective double-blinded parallel randomized controlled trial (RCT) which is considered the gold standard and the most reliable type of studies as it inherently corrects for unknown confounders and minimizes investigator bias [14]. Randomization makes the groups of the study as similar as possible and allows each patient to take the same chance of being assigned to either the intervention or the comparator group without any choice of the operator [15]. Apart from randomization, bias can be reduced by allocation concealment, blinding and minimizing the loss to follow up [16].

In this study, patients with symptomatic irreversible pulpitis were selected as the main inclusion criterion, excluding those cases associated with symptomatic/asymptomatic apical periodontitis, since the initial diagnosis of the periapical tissues has a significant effect on the post-endodontic pain [17].

Mandibular permanent molars were selected in the present study to avoid possible confounding factors on the outcome due to variations in tooth type. Compared to the maxilla, postopera- 
Comparison of Postoperative Pain after Root Canal Instrumentation Using M-Pro and ProTaper Next in Molars with Symptomatic Irreversible Pulpitis: A Randomized Clinical Trial

tive pain in the mandible was found to be substantially higher because the mandible has a thick trabecular pattern, thus decreasing blood flow and resulting in more inflammatory localization, which may slow the healing process [18]. Furthermore, only mandibular molars with 4 root canals were selected for this study to avoid the possible effect of apical preparation size as a confounder. All canals were prepared to an apical size of $0.25 \mathrm{~mm}$.

Treatment was completed in a single visit which has several advantages including reduction in the number of appointments and treatment cost, familiarity with internal root canal anatomy, avoidance of inter-appointment contamination and bacterial regrowth resulting in pain and reinfection of the canals as a sequence of bacterial ingress from a leaky temporary restoration [19].

The working length was determined by Root ZX electronic apex locator, because of its high accuracy $[20,21]$. then confirmed by the radiograph. This prevents over-instrumentation that may result in postoperative pain and flare-up following endodontic treatment [19].

Optimal pain management requires an appropriate assessment of pain which can be done with the help of various pain rating scales. In the current study, Numerical Rating Scale (NRS) was used for measuring the pain intensity for its higher compliance rates, better responsiveness and ease of use, and good applicability relative to other pain scales [22]. In addition, NRS has been commonly used as the outcome measure in different studies evaluating postoperative pain after root canal treatment $[23,24]$.

The patients were given a capsule of placebo to be taken in the event of mild pain, Ethical practice indicates that rescue medication should be prescribed for participants to use if the pain persisted after taking the placebo [25]. Therefore, Ibuprofen (400mg) was prescribed to be administrated in case of an emergency. Analgesics were only prescribed as on-demand analgesics and not a regular prescription of medication since it would influence the outcome measures of this study [26].

This clinical trial showed no statistically significant difference between the two groups demographically; age and gender; where $p=0.297$ and $p=1.0$ respectively. This provided an even baseline so that only the shaping instrument technique would remain as the key and distinguishing factor allowing for adequate comparison of the effect of the intervention in both groups. Furthermore, there was no statistically significant difference regarding tooth type between the two groups $(\mathrm{p}=0.221)$.

In our study, no statistically significant difference was found between the postoperative pain NRS scores or analgesic intake of both M-Pro and ProTaper Next groups at the different follow-up time intervals.

Whereas some studies deducted that using controlled memory files resulted in less debris extrusion [27,28], others have reported that it may lead to more debris extrusion [29,30]. However, another study [31] found no significant difference between ProTaper Next, Hyflex CM and M-Pro regarding debris extrusion. This remarked discrepancy could be attributed to differences in the cross-section, cutting-edge design, taper, tip type, configuration, flexibility, alloy type, number of used files, kinematics, or cutting efficacy [32].

Although there was no statistically significant difference between the 2 groups regarding postoperative pain, it is worth noting that M-Pro rotary files have several design features that may result in lower debris extrusion. M-Pro files have a convex triangular cross-section. This cross-section results in less debris extrusion compared with other instruments due to greater debris loading [33]. Furthermore, it may also influence screw-in tendency which in turn affects debris extrusion. It was found that square to rectangular cross-section files had a higher screw-in tendency compared with a triangular cross-section [34].

M-Pro files are controlled memory files system manufactured from (X-wire). Controlled memory files possess less cutting efficiency which results in less debris collected in the apical area with less possibility of debris extrusion during preparation [35].

Interestingly, Elnahas., et al. [36] compared the intensity of postoperative pain after instrumentation with ProTaper Next files or Neolix files (controlled memory files) and found no statistically significant difference at 6, 12 and 24 hours. However, at 48 hours, the Neolix group showed a statistically significant lower mean pain score than the ProTaper Next group. The mean pain scores in the Neolix group were lower at all observation periods which comes in accordance with our study in which mean pain scores were lower in the M-Pro group (controlled memory files) for most of the observation periods $(12,48$ and 72 hours) although there was no statistically significant difference between the two groups. 


\section{Conclusion}

Postoperative pain resulting from the use of M-Pro rotary was comparable to ProTaper Next rotary files and M-Pro files can be viewed as a promising, more economical instrument for root canal shaping.

\section{Conflict of Interest}

The authors deny any conflicts of interest in this study.

\section{Bibliography}

1. Nekoofar M H., et al. "Evaluation of Meloxicam (a Cox-2 Inhibitor) for Management of Postoperative Endodontic Pain: A Double-Blind Placebo-Controlled Study". Journal of Endodontics 29.10 (2003): 634-637.

2. Pochapski M T., et al. "Effect of Pretreatment Dexamethasone on Postendodontic Pain". Oral Surgery, Oral Medicine, Oral Pathology, Oral Radiology and Endodontics 108.5 (2009): 790795.

3. Christopher U and Emmanuel A. "Flare-up Incidence and Related Factors in Adults". Journal of Dentistry and Oral Hygiene 12.2 (2010): 120-123.

4. Shahi S., et al. "Postoperative Pain after Endodontic Treatment of Asymptomatic Teeth Using Rotary Instruments: A Randomized Clinical Trial”. Iranian Endodontic Journal 11.1 (2016): 38-43.

5. Ferraz C C., et al. "Apical Extrusion of Debris and Irrigants Using Two Hand and Three Engine-Driven Instrumentation Techniques". International Endodontic Journal 34.5 (2001): 354-358.

6. Pak J G and S N White. "Pain Prevalence and Severity before, During, and after Root Canal Treatment: A Systematic Review". Journal of Endodontics 37.4 (2011): 429-438.

7. Burklein S and E Schafer. "Apically Extruded Debris with Reciprocating Single-File and Full-Sequence Rotary Instrumentation Systems". Journal of Endodontics 38.6 (2012): 850-852.

8. Seeddent Co, Ltd. "Dental Mpro Files" (2020).

9. Ruddle C J., et al. "The Shaping Movement: Fifth-Generation Technology". Dentistry today 32.4 (2013): 94-99.

10. Nekoofar M H., et al. "Comparison of the Effect of Root Canal Preparation by Using Waveone and Protaper on Postoperative Pain: A Randomized Clinical Trial". Journal of Endodontics 41.5 (2015): 575-578.
11. Gambarini G., et al. "The Influence of Three Different Instrumentation Techniques on the Incidence of Postoperative Pain after Endodontic Treatment". Annali di Stomatologia (Roma) 4.1 (2013): 152-155.

12. Relvas J B., et al. "Assessment of Postoperative Pain after Reciprocating or Rotary Niti Instrumentation of Root Canals: A Randomized, Controlled Clinical Trial". Clinical Oral Investigetions 20.8 (2016): 1987-1993.

13. Western J S and D D Dicksit. "Apical Extrusion of Debris in Four Different Endodontic Instrumentation Systems: A Meta-Analysis". Journal of Conservative Dentistry 20.1 (2017): 30-36.

14. Evans D. "Hierarchy of Evidence: A Framework for Ranking Evidence Evaluating Healthcare Interventions". Journal of Clinical Nursing 12.1 (2003): 77-84.

15. Farrugia P., et al. "Practical Tips for Surgical Research: Research Questions, Hypotheses and Objectives". Canadian Journal of Surgery 53.4 (2010): 278-281.

16. Kao L S., et al. "Clinical Research Methodology I: Introduction to Randomized Trials". Journal of the American College of Surgeons 206.2 (2008): 361-369.

17. Alves Vde 0. "Endodontic Flare-Ups: A Prospective Study". Oral Surgery, Oral Medicine, Oral Pathology, Oral Radiology and Endodontics 110.5 (2010): 68-72.

18. Martin-Gonzalez J., et al. "Influence of Root Canal Instrumentation and Obturation Techniques on Intra-Operative Pain During Endodontic Therapy". Medicina Oral Patologia Oral Y Cirugia Bucal 17.5 (2012): 912-918.

19. Priyank H., et al. "Assessment of the Incidence of Posttreatment Endodontic Flare-Ups in Patients Undergoing SingleSitting Root Canal Therapies: A Clinical Study". The Journal of Contemporary Dental Practice 17.10 (2016): 849-852.

20. Zand V., et al. "Accuracy of Working Length Determination Using Novapex and Root-Zx Apex Locators: An in Vitro Study". The Journal of Contemporary Dental Practice 18.5 (2017): 383385.

21. Vanitha S and I A Sherwood. "Comparison of Three Different Apex Locators in Determining the Working Length of Mandibular First Molar Teeth with Irreversible Pulpitis Compared with an Intraoral Periapical Radiograph: A Block Randomized, Controlled, Clinical Trial". Journal of Investigative and Clinical Dentistry 10.3 (2019): 12408.

22. Hjermstad M J., et al. "Studies Comparing Numerical Rating Scales, Verbal Rating Scales, and Visual Analogue Scales for Assessment of Pain Intensity in Adults: A Systematic Litera- 
ture Review". Journal of Pain and Symptom Managament 41.6 (2011): 1073-1093.

23. Jorge-Araújo A C. A., et al. "Effect of Premedication with AntiInflammatory Drugs on Post-Endodontic Pain: A Randomized Clinical Trial". Brazilian Dental Journal 29.3 (2018): 254-260.

24. Lopes L P B., et al. "Effect of Photobiomodulation Therapy on Postoperative Pain after Endodontic Treatment: A Randomized, Controlled, Clinical Study". Clinical Oral Investigations 23.1 (2019): 285-292.

25. Millum J and C Grady. "The Ethics of Placebo-Controlled Trials: Methodological Justifications". Contemporary Clinical Trials 36.2 (2013): 510-514.

26. Topçuoğlu H S., et al. "The Effect of Different Irrigation Agitation Techniques on Postoperative Pain in Mandibular Molar Teeth with Symptomatic Irreversible Pulpitis: A Randomized Clinical Trial". Journal of Endodontics 44.10 (2018): 14511456.

27. Labbaf H., et al. "An in Vitro Comparison of Apically Extruded Debris Using Reciproc, Protaper Universal, Neolix and Hyflex in Curved Canals". Iranian Endodontic Journal 12.3 (2017): 307-311.

28. Hadi A W and MR Hameed. "Comparative Study of the Amount of Apically Extrusion of Debris During Root Canal Preparation Using Wave Onetm, Trushape $3 \mathrm{dtm}$, Hyflextm $\mathrm{Cm}$ and One Shapetm Instrumentation Systems: An in Vitro Study". Journal of Baghdad College of Dentistry 29.1 (2017): 1-8.

29. Capar I D., et al. "An in Vitro Comparison of Apically Extruded Debris and Instrumentation Times with Protaper Universal, Protaper Next, Twisted File Adaptive, and Hyflex Instruments". Journal of Endodontics 40.10 (2014): 1638-1641.

30. Uzun I., et al. "Apical Extrusion of Debris Using Reciprocating Files and Rotary Instrumentation Systems". Nigerian Journal of Clinical Practice 19.1 (2016): 71-75.

31. El Khodary., et al. "Influence of Different Rotary Systems on the Amount of Apically Extruded Debris in Mandibular Molars (an in Vitro Study)". Egyptian Dental Journal 65.2 (2019): 16631670 .

32. Mollashahi N F., et al. "Comparison of Postoperative Pain after Root Canal Preparation with Two Reciprocating and Rotary Single-File Systems: A Randomized Clinical Trial". Iranian Endodontic Journal 12.1 (2017): 15-19.

33. Nevares G., et al. "Apical Extrusion of Debris Produced During Continuous Rotating and Reciprocating Motion". The Scientific World Journal 2015 (2015): 267264.
34. Ha JH., et al. "'Screw-in' Tendency of Rotary Nickel-Titanium Files Due to Design Geometry". International Endodontic Journal 48.7 (2015): 666-672.

35. Kocak M M., et al. "Comparison of Protaper Next and Hyflex Instruments on Apical Debris Extrusion in Curved Canals". International Endodontic Journal 49.10 (2016): 996-1000.

36. Elnahas K., et al. "Post-Operative Pain after Single Visit Root Canal Treatment in Necrotic Teeth Using Two Different Rotary Systems Protaper Next and Neolix: A Randomized Clinical Trial". Acta Scientific Dental Sciences 3.4 (2019): 110-115.

\section{Assets from publication with us}

- Prompt Acknowledgement after receiving the article

- Thorough Double blinded peer review

- Rapid Publication

- Issue of Publication Certificate

- High visibility of your Published work

Website: www.actascientific.com/

Submit Article: www.actascientific.com/submission.php Email us: editor@actascientific.com

Contact us: +919182824667 